\title{
Differences in stakeholders' and end users' preferences of arsenic mitigation options in Bangladesh
}

\author{
Mohammad Mojahidul Hossain • Jennifer Inauen
}

Received: 11 December 2013 / Accepted: 8 May 2014 / Published online: 31 May 2014

(C) Springer-Verlag Berlin Heidelberg 2014

\begin{abstract}
Aim Arsenic contamination of drinking water is a public health crisis. Since its detection in Bangladesh, the world's most arsenic-affected country, organizations involved (i.e., stakeholders) have made great efforts by testing wells and installing safe water options. Yet, 20 million Bangladeshi are still at risk. It has been suggested that the discrepancy between stakeholders' and end users' preferences of arsenic mitigation options is one reason for the slow progress. Therefore, this study aimed at comparing stakeholders' and end users' preferences. Subjects and methods Three investigations were conducted in Bangladesh: a series of qualitative interviews with 22 stakeholders and two end user surveys with a total of 1,268 randomly selected households living in six arsenic-affected districts of Bangladesh.

Results Stakeholders mostly preferred rural piped water supplies and deep tubewells, while their least preferred options were dug wells and arsenic removal filters. End users mostly preferred deep tubewells, well-sharing and rural piped water supplies, while dug wells were least preferred. End users identified several disadvantages of mitigation options, including long distances, great effort to collect water and difficult social situations. They further demonstrated moderate willingness to pay for a rural piped water supply, deep tubewells and pond sand filters, but lower willingness for other options. Conclusion Stakeholders' and end users' preferences converged for deep tubewells and rural piped water supplies,
\end{abstract}

\footnotetext{
M. M. Hossain $(\triangle)$

Environmental Social Sciences, Eawag: Swiss Federal Institute of Aquatic Science \& Technology, Überlandstrasse 133, P.O. Box 611, 8600 Dübendorf, Switzerland

e-mail: mhossain_1979@yahoo.com

J. Inauen

Department of Psychology, University of Zurich, Zurich, Switzerland
}

while well-sharing was preferred by end users, but not by stakeholders. The results suggest installing deep tubewells and rural piped water supplies with greater priority. Furthermore, stakeholders' preferences to promote well-sharing should be enhanced.

Keywords Arsenic mitigation options · Stakeholders · End users $\cdot$ Preferences $\cdot$ Willingness to pay $\cdot$ Bangladesh

\section{Introduction}

Arsenic has become a global public health threat. The risk of arsenic poisoning of groundwater has been reported by more than 70 countries from 6 continents so far (Bala et al. 2012; United Nations Children's Fund [UNICEF] et al. 2010). It was estimated that over 200 million people worldwide are at the risk of drinking water from sources with arsenic concentrations above the World Health Organization (WHO) recommended level of $10 \mu \mathrm{g} / \mathrm{l}$ (Bala et al. 2012; Naujokas et al. 2013; WHO 2008). The severity of this issue is much higher in South and Southeast Asia than in other regions; overall, Bangladesh is the world's most arsenic-affected country (Bhattacharjee 2007; UNICEF et al. 2010). In Bangladesh, the occurrence of high arsenic levels in groundwater is mainly linked to the natural geological source(s) (Anawar et al. 2011; Hossain 2006). The excessive arsenic contamination of groundwater is found in most areas in the country, with 47 districts featuring more than $5 \%$ and 6,062 villages featuring 80 to $99 \%$ contaminated tubewells (Johnston and Sarker 2007). Most Bangladeshi people (70.9 \%) rely on drinking water from shallow tubewells, even though shallow aquifers ( $<150 \mathrm{~m}$ depth) are mostly prone to arsenic contamination (Ahmed et al. 2004; Bangladesh Bureau of Statistics [BBS] and UNICEF 2011). In Bangladesh, 52 million people were recently estimated to be at risk of drinking arsenic- 
contaminated water above the WHO standard of $10 \mu \mathrm{g} / \mathrm{l}$, while 22 million were exposed to risk relative to the Bangladesh national guideline of $50 \mu \mathrm{g} / 1$ (BBS and UNICEF 2011; Flanagan et al. 2012). It was also estimated that as many as 5.6 million people may be drinking water with an arsenic content of above $200 \mu \mathrm{g} / \mathrm{l}$ (BBS and UNICEF 2011; Flanagan et al. 2012). Intake of excessive arsenic-contaminated water can cause adverse health effects, which are summarized under the term of arsenicosis, which develops slowly over a period of several years. Arsenicosis includes various skin diseases (Argos et al. 2011; Smith and Steinmaus 2009; WHO 2001), several forms of cancer (Chen and Ahsan 2004; Smith and Steinmaus 2009; WHO 2001), reproductive and neurodevelopmental defects (Ahmad et al. 2001; Parvez et al. 2011; Smith and Steinmaus 2009; Wasserman et al. 2004) as well as other chronic diseases, such as peripheral vascular diseases, cardiovascular diseases (Chen et al. 2011; Smith and Steinmaus 2009; WHO 2001) and mortality (Argos et al. 2010; Chen et al. 2011; Flanagan et al. 2012; Smith and Steinmaus 2009). In Bangladesh, 42,700 to 56,400 deaths per year were estimated to be attributable to arsenic intake via drinking water (Flanagan et al. 2012). The socioeconomic effects of the disease are also severe (Hassan et al. 2005), particularly for women (Hanchett 2006; Naujokas et al. 2013). They include social stigmatization and discrimination, difficulties getting married and decreased working ability (Brinkel et al. 2009; Hassan et al. 2005; Sarker 2010).

\section{Arsenic mitigation in Bangladesh}

A great number of stakeholders have been playing a vital role in arsenic mitigation since the first detection of arsenic in Bangladesh in the 1990s. The most important of these are the Department of Public Health Engineering (DPHE) of the Government of Bangladesh (GoB) and its supporting bilateral and multilateral agencies, such as the World Bank (WB), UNICEF, as well as numerous international and national non-governmental organizations (NGOs; DPHE 2013; Milton et al. 2012). A nationwide tubewell screening program was conducted between 2000 and 2006 that tested over half of the total wells in the country (approximately 5 million). The ones with arsenic levels below the Bangladeshi standard $(50 \mu \mathrm{g} / \mathrm{l})$ were labeled safe and painted green, while those levels in excess were labeled unsafe and painted red (Johnston and Sarker 2007).

In 2004, the GoB formulated a policy and implementation plan for arsenic mitigation, which identified several arsenic mitigation options: dug wells, pond sand filters, large-scale surface water treatment, rainwater harvesting systems, deep tubewells, rural piped water supply and arsenic removal filters (GoB 2004a; b). At the end of 2009, the GoB approved six arsenic removal filters (Johnston et al. 2010), including the Alcan, Read-F, Sono and Sidko filters (UNICEF et al. 2010). Furthermore, well-sharing (i.e., switching to a neighbor's arsenic-safe shallow tubewell) was identified as an important arsenic mitigation option (e.g., Ahmed et al. 2006; Inauen et al. 2013a; van Geen et al. 2002).

In the last decade, a large number of arsenic mitigation options have been implemented and installed in arseniccontaminated areas by both governmental and nongovernmental agencies (Kabir and Howard 2007). Even though the national policy and implementation plan prioritized surface water options (e.g., rural piped water supply, dug well, pond sand filter) over groundwater options (e.g., deep tubewells), stakeholders have been mostly implementing deep tubewells (Ahmed et al. 2006). It was estimated that during 2000 to 2009 , more than 160,000 safe water devices were installed in arsenic-prone areas (UNICEF 2010). However, many of the installed mitigation options are not maintained or used regularly (Hoque et al. 2004; Inauen et al. 2013a).

Use and preference of arsenic mitigation options in Bangladesh

Indicating poor acceptance by end users, a survey of the technical performance of 1,000 arsenic-safe water options revealed that $83 \%$ of arsenic removal technologies, $33 \%$ of rainwater-harvesting systems, $25 \%$ of dug wells and pond sand filters, and $10 \%$ of deep tubewells were non-functional because of maintenance or other problems (Kabir and Howard 2007). The study also found that $50 \%$ of the functional options suffered periodic breakdowns (Kabir and Howard 2007). Inauen and colleagues (2013a), on the other hand, identified that more than a third of arsenic-affected households with access to one or more mitigation options in Bangladesh were not using these alternatives. It was also specified that $63.4 \%$ people with access to rainwater harvesters, around half of the population with access to dug wells, pond sand filters and deep tubewells, a quarter of the households with access to community filters and well switching and $14.4 \%$ with access to rural piped water supply were not using these arsenic mitigation options (Inauen et al. 2013a).

It is further notable that awareness is often insufficient to motivate people to switch to arsenic-safe water options. In a study by Hoque and colleagues (2004), for instance, $64 \%$ of study participants continued to drink arsenic-contaminated water, even though $78 \%$ of them knew about the health risks. Another study of 150 arsenicosis patients showed that $25 \%$ were consuming water from contaminated wells, even though $91 \%$ were aware that arsenic-contaminated water can cause diseases (Mitra et al. 2002). Regarding the issue of willingness to switch to safe water sources, $92 \%$ indicated their intentions to reduce their exposure, but only $46.2 \%$ actually switched to a safe well (Parvez et al. 2006). Regarding distance, most ( $80 \%$ ) of the rural women were not willing to walk for more than 5 min to collect arsenic-safe water (Nahar et al. 2008). So, people still have a strong preference for tubewell water, 
even if it is known to be contaminated. Further identified issues related to the rejection of arsenic-safe water options include dissatisfaction with water quality (e.g., taste, temperature and smell; Inauen et al. 2013a; Kabir et al. 2005), water unavailability throughout the year (Alam and Rahman 2010), use restrictions by the caretaker of the safe option (Kabir et al. 2005), lack of favorable social norms (Inauen et al. 2013a; Mosler et al. 2010) and social barriers affecting women (Hoque et al. 2004; Mosler et al. 2010).

In addition, the economic factors, e.g., high operation and maintenance costs (Hoque et al. 2004; Shafiquzzaman et al. 2009) and peoples' affordability (Ahmad et al. 2005), can be a major concern for accepting a mitigation option. For example, the cost of serving 50 households with a community arsenic removal filter would amount to $150,000-300,000$ Bangladeshi Taka [BDT; approximately 1,956-3,911 US dollars (US\$) (UNICEF et al. 2010)]. Similarly, 3,000-6,000 BDT (approximately US\$39-78) is required to provide a single household with household filters, which is almost double the cost of a deep tubewell, dug well or pond sand filter (UNICEF et al. 2010). A particularity in Bangladesh is that most of the water options are installed with heavy subsidies and can be used free of charge [Johnston et al. 2010; Policy Support Unit (PSU) and Local Government Division (LGD) 2011; UNICEF 2011]. A study of eight arsenic mitigation options reported that $44 \%$ of users and $16 \%$ of non-users of these options paid for their installation (Inauen et al. 2013a). However, the contributions differed between mitigation options (Inauen et al. 2013a). Most households only contributed 700 BDT or less (approximately US\$9; Inauen et al. 2013a). In turn, paying for monthly use was found common only for piped water and community arsenic removal filters (Inauen et al. 2013a). Another study showed that one-third of the households were not willing to pay any money for monthly use of arsenic-safe water, while approximately half of the surveyed households were willing to pay up to 50 BDT (approximately US\$0.70; Nahar et al. 2008). This would be enough to cover the monthly cost of a rural piped water supply for one household (Inauen et al. 2013a). Similarly, Shafiquzzaman and colleagues (2009) found that $70 \%$ of their respondents were unwilling to pay for the cost of a Sono filter, and the remaining $30 \%$ were willing to pay only $77-$ 384 BDT (approximately US $\$ 1-5$ ), which was very much lower than the actual price, 2,700 BDT (approximately US\$35; UNICEF et al. 2010). For the maintenance and monitoring of water quality, $70 \%$ of their interviewees were not willing to pay any money, and $30 \%$ were willing to pay only 77-153 BDT (approximately US\$1-2; Shafiquzzaman et al. 2009). In summary, past research indicates that people are willing to pay for options with easier and cheaper operation and maintenance, easy access (requiring less time and effort to collect water) and offering good water quality.
Overall, the above-presented research on arsenic mitigation in Bangladesh demonstrates the vastness and complexity of the arsenic crisis. Some major achievements have been made, but in comparison to the very successful promotion of shallow tubewells in the 1970s, arsenic mitigation is going slowly. It has been argued that one reason for this is the uncertainty about which mitigation options should be installed with priority (Atkins et al. 2007a). On the one hand, there is an ongoing debate among stakeholders about the best mitigation option (Atkins et al. 2007b). On the other hand, it has been documented that mitigation is likely to fail if end users' preferences concerning mitigation options are not taken into account (Bhattacharjee 2007; Mosler et al. 2010; Inauen et al. 2013a). Therefore, this study aims at providing a more comprehensive comparison of stakeholders' and end users' preferences concerning arsenic mitigation options. Additionally, it would be helpful to know more about the challenges to arsenic mitigation perceived from both the stakeholders' and end users' perspectives, as this should help focus resources on the most pressing issues. Finally, in order to develop sustainable mitigation measures, it is important to consider economic preferences related to arsenic mitigation, i.e., people's willingness to pay for each option and for arsenic testing. The research questions are:

(1) Which arsenic mitigation options are preferred by both stakeholders and end users? For which options do their preferences differ?

(2) What advantages and disadvantages do stakeholders and end users perceive for each arsenic mitigation option?

(3) Are there any differences between the actual costs and end users' willingness to pay for installing or using arsenic mitigation options as well as testing for arsenic?

\section{Methods}

This research employed a mixed methods approach consisting of qualitative and quantitative interviews. Overall, three surveys were conducted in Bangladesh between 2008 and 2010: qualitative interviews with 22 stakeholder and two end user surveys with a total of 1,268 randomly selected households. The methodology is presented separately for the stakeholder interviews and end user surveys in the following.

Study area, participants and procedures

\section{Stakeholder interviews}

Qualitative interviews with representatives of 22 organizations (Table 1) concerned with arsenic mitigation in 
Bangladesh were conducted mainly in Dhaka, but also in other locations in Bangladesh in August 2008. In sum, stakeholders were defined as organizations that had any legitimate interest or project (in the past, present or future) in arsenicrelated issues in Bangladesh (DPHE 2013; Milton et al. 2012). The aim was to select stakeholders from different levels of the social system: the central GoB, local governmental institutions, bilateral and multilateral agencies, international and local NGOs, as well as research institutions. Organizations were purposefully selected according to their importance in arsenic mitigation, as well as their compliance and availability. Of the 26 stakeholders contacted for interviews, 3 were not interviewed because they were unavailable during the data collection period [World Bank, Bangladesh Rural Advancement Committee (BRAC) headquarters and Manobik Sakti Unnayan Kendro]. One stakeholder refused the interview (DPHE headquarters). Both of the authors were involved in locating and contacting the stakeholders, conducting the interviews with a semi-structured interview guideline and taking notes.

\section{End user surveys}

For investigating end users' preferences, unpublished data from a larger study were used (Inauen et al. 2013a, for details on the overall methodology). Two household surveys were conducted with a total of 1,268 randomly selected households living in arsenic-affected areas of rural Bangladesh (Table 1). To determine the sample size, GPOWER (Erdfelder et al. 1996) was used for the statistical procedures employed in the previously published studies (Inauen et al. 2013a, b). Survey 1 was conducted in November 2009 with a sample size of 872 and survey 2 in December 2010, with a sample size of 396 households, respectively. Six highly arsenic-affected districts, Comilla, Munshiganj, Brahmanbaria, Khulna, Satkhira and Bagerhat, were selected for survey 1 . All households were presently or had previously been drinking water from arsenic-contaminated wells (i.e., were at risk) and had access to at least one of seven arsenic mitigation options: a rural piped water supply, community arsenic removal filters, household arsenic removal filters, household rainwater harvesting, dug wells, pond sand filters and well-sharing. Survey 2 was conducted in the Comilla district. The only available arsenic mitigation in the study region was deep tubewells. It should also be noted that all groups of surveyed households had similar types of sociodemographic characteristics, although the incomes varied between the regions (Inauen et al. 2013a, for details). Households were selected via random-route sampling (Hoffmeyer-Zlotnik 2003). If the household met the aforementioned inclusion criteria (i.e., was at risk of drinking arsenic-contaminated water and had access to an arsenic mitigation option), verbal informed consent was obtained from the person responsible for water collection (usually a woman, Inauen et al. 2013a). The face-to-face interviews of approximately 1-h duration were conducted by experienced and trained Bangladeshi interviewers using a structured questionnaire.

Questionnaire and measures

\section{Stakeholder interviews}

A semistructured interview guideline was developed. The questions relevant to the present study are displayed in Table 2 . Because this approach was qualitative, all questions were asked openly in order to yield more detailed insight into stakeholders' perceptions. Stakeholders were asked to answer the questions according to the preference of their organization.

In addition to the interviews, relevant information was collected from different online sources to estimate the installation costs (both actual and subsidized) and monthly use costs (i.e., a fee for the caretaker, electricity bill, any maintenance cost or replacement of the filter media, etc.) of mitigation options as well as arsenic testing cost (both laboratory and discount). Google Scholar was used for this purpose as well as stakeholders' websites. The following key words (and combinations thereof) were employed in the search: arsenic, mitigation, option, preference, people, stakeholder, Bangladesh, willingness to pay and cost.

\section{End user surveys}

The surveys were conducted using a structured questionnaire with supplementary qualitative questions (Inauen et al. 2013a, for details). In the present study, contrasting the Inauen et al. (2013a) investigation, the qualitative items were analyzed, because they provide detailed information on people's preferences. See Table 2 for an overview of the assessment questions of interest here. Note that similar questions were used in both surveys, but some items differed (Table 2). Willingness to pay (WTP) was assessed for installing and using an arsenic mitigation option or arsenic testing. Which of these questions was asked depended on the relevancy for the specific arsenic mitigation option to which the respondent had access. WTP for installing an option was only assessed for household filters and rainwater harvesting, because these options are the only ones to which most users contribute money (Inauen et al. 2013a).

\section{Data analysis}

Frequencies were computed with SPSS 18.0 and Microsoft Excel 2007. For the WTP analyses, the medians were computed rather than the mean because the data were not normally distributed. 
Table 1 Stakeholders and number of households interviewed

\begin{tabular}{|c|c|c|c|}
\hline \multicolumn{2}{|l|}{ Stakeholders $(N=22)$} & \multicolumn{2}{|l|}{ End users $(N=1,268)$} \\
\hline Type of stakeholder & Organizations interviewed & $\begin{array}{l}\text { No. of households per arsenic mitigation } \\
\text { option to which they had access }\end{array}$ & $\mathrm{N}$ \\
\hline \multirow[t]{2}{*}{ Local government } & (1) DPHE Sreenagar Upazila, Munshiganj district & Survey $1(N=872)$ & \\
\hline & (2) Union Parishad, Kayla Union, Satkhira district & (1) Rural piped water supply & 125 \\
\hline \multirow[t]{3}{*}{ Bilateral agencies } & (3) Policy Support Unit (PSU) & (2) Pond sand filters & 124 \\
\hline & (4) Swiss Agency for Development \& Cooperation (SDC) & (3) Dug wells & 124 \\
\hline & (5) Japan International Cooperation Agency (JICA) & (4) Rainwater harvesting & 123 \\
\hline \multirow[t]{2}{*}{ Multilateral agencies } & (6) United Nations Children's Fund (UNICEF) & (5) Community arsenic removal filters & 125 \\
\hline & (7) World Health Organization (WHO) & (6) Household arsenic removal filters & 126 \\
\hline \multirow[t]{3}{*}{ International NGOs } & (8) Asia Arsenic Network (AAN) & (7) Well-sharing & 125 \\
\hline & (9) Swiss Red Cross & Survey $2(N=396)$ & \\
\hline & (10) WaterAid Bangladesh & (8) Deep tubewells & 396 \\
\hline \multirow[t]{8}{*}{ Local NGOs } & (11) NGO Forum for Drinking Water Supply \& Sanitation & & \\
\hline & (12) Bangladesh Rural Advancement Committee (BRAC) & & \\
\hline & (13) Village Education Resource Center (VERC) & & \\
\hline & (14) Village Integrated Development Association (VIDA) & & \\
\hline & (15) Grameen Shikkha & & \\
\hline & (16) Bangladesh Shrimp \& Fish Foundation (BSFF) & & \\
\hline & (17) Shushilan & & \\
\hline & (18) Dhaka Community Hospital Trust (DCHT) & & \\
\hline \multirow[t]{2}{*}{ Research institutions } & (19) Bangladesh Institute of Development Studies (BIDS) & & \\
\hline & (20) Bangladesh University of Engineering \& Technology (BUET) & & \\
\hline \multirow[t]{2}{*}{ Other institutions } & (21) Upazila Health Complex Sreenagar, Munshiganj & & \\
\hline & (22) Bangladesh Water Supply Program Project (BWSPP) & & \\
\hline
\end{tabular}

Ethics statement

This study was conducted in strict accordance with the ethical principles of the American Psychological Association (APA) and the Declaration of Helsinki. It underlies the ethics review board of the ETH, Swiss Federal Institute of Technology Zurich. This review board exempts the survey studies that do not comprise an intervention from obtaining an ethical approval: http://www.vpf.ethz.ch/about/commissions/EK (Inauen et al. 2013a, for details).

\section{Results}

Preferences of arsenic mitigation options

Rural piped water supply emerged as stakeholders' most preferred option (Table 3). Almost as many stakeholders $(22.7 \%)$ favored deep tubewells, but many others $(27.3 \%)$ preferred it less. Stakeholders were rather divided regarding their preferences concerning the other options.
Interstingly, well-sharing was not named by any stakeholder as a preferable mitigation option, but it emerged as highly preferred in end user survey 1. End users in survey 2, in turn, almost unanimously named deep tubewells as their most preferred option.

Advantages and disadvantages of arsenic mitigation options

Paralleling the above findings, stakeholders named the most advantages for rural piped water supply (Table 4) and few disadvantages (Table 5). They thought that a rural piped water supply offered some technical advantages, such as improved monitoring, but considered economic challenges of installing them as a drawback. Stakeholders also mentioned many advantages of deep tubewells, but again consistent with the preference ratings, they mentioned several disadvantages, including concerns of groundwater depletion, limited technical feasibility and high cost.

End users perceived different aspects of the mitigation options as advantageous or disadvantageous compared to stakeholders. That the options provided arsenic-safe water was often described as a primary advantage of the options. 
Table 2 Study items and their assessment

\begin{tabular}{|c|c|c|}
\hline \multirow[t]{2}{*}{ Assessment items } & \multicolumn{2}{|l|}{ Assessment questions } \\
\hline & Stakeholders & End users \\
\hline $\begin{array}{l}\text { Preferences of arsenic } \\
\text { mitigation options }\end{array}$ & $\begin{array}{l}\text { - Which arsenic mitigation option does } \\
\text { your organization prefer most? } \\
\text { - Which arsenic mitigation option is } \\
\text { less preferable? }\end{array}$ & $\begin{array}{l}\text { - Survey 1: Which is your most preferred arsenic-safe water option? } \\
\text { - Survey 2: Which water do you prefer for drinking? (all water options were offered } \\
\text { for choosing the most preferable one) }\end{array}$ \\
\hline $\begin{array}{l}\text { Advantages of arsenic } \\
\text { mitigation options }\end{array}$ & $\begin{array}{l}\text { - What are the advantages of this } \\
\text { arsenic mitigation option? }\end{array}$ & $\begin{array}{l}\text { - Survey 1: What are the advantages of using water from the [mitigation option]? } \\
\text { - Survey } 2 \text { : What are the advantages of collecting water from the deep tubewells? }\end{array}$ \\
\hline $\begin{array}{l}\text { Disadvantages of } \\
\text { arsenic mitigation } \\
\text { options }\end{array}$ & $\begin{array}{l}\text { - What are the disadvantages of this } \\
\text { arsenic mitigation option? }\end{array}$ & $\begin{array}{l}\text { - Survey 1: What are the disadvantages of using water from the [mitigation option]? } \\
\text { - Survey 2: What are the disadvantages of collecting water from the deep tubewells? }\end{array}$ \\
\hline \multicolumn{3}{|c|}{ Actual costs and end users' willingness to pay for installing or using arsenic mitigation options and testing of arsenic: } \\
\hline & Actual costs & End users' willingness to pay \\
\hline For installing option & Literature review & $\begin{array}{l}\text { - Survey 1: only for household filters and rainwater harvesting system } \\
\text { What would be the maximum and reasonable amount you would be willing to pay } \\
\text { for a new household filter or installation of a rainwater harvesting system? }\end{array}$ \\
\hline For using option/month & Literature review & $\begin{array}{l}\text { - Survey 1: } \\
\text { For rural piped water supply, pond sand filters, community filters, dug wells: What } \\
\text { would be the maximum/reasonable amount you would be willing to pay for water } \\
\text { from [mitigation option] per month? } \\
\text { For household filters: What would be the maximum/reasonable amount you would } \\
\text { be willing to pay for a refill of the filter media? }\end{array}$ \\
\hline Water testing for arsenic & Literature review & $\begin{array}{l}\text { - Survey 1: for household filters, well-sharing } \\
\text { What would be the maximum/reasonable amount you would be willing to pay for an } \\
\text { arsenic test of your water source? }\end{array}$ \\
\hline
\end{tabular}

Of further importance was water quality in terms of taste, temperature, color and smell. End users also appreciated that some of the mitigation options were effective to reduce iron levels, particularly rainwater harvesting. In turn, recurring themes in end users' reports of disadvantages were limited water availability (particularly for the rural piped water supply), increased distance and effort to collect water (particularly for community options, including deep tubewells), cumbersome maintenance procedures (particularly for household arsenic removal filters) and social barriers of meeting people (particularly for community options).

Table 3 Preferences of arsenic mitigation options

\begin{tabular}{|c|c|c|c|c|c|c|c|}
\hline \multicolumn{2}{|l|}{ Stakeholders $(N=22)$} & \multicolumn{2}{|l|}{ Stakeholders $(N=22)$} & \multicolumn{2}{|l|}{ End users, study $1(N=872)$} & \multicolumn{2}{|c|}{ End users, study $2(N=396)$} \\
\hline Most preferred & $f(\%)$ & Less preferred & $f(\%)$ & Most preferred & $f(\%)$ & $\begin{array}{l}\text { Most preferred } \\
\text { for drinking }\end{array}$ & $f(\%)$ \\
\hline $\begin{array}{l}\text { - Rural piped } \\
\text { water supply }\end{array}$ & $6(27.3)$ & - Deep tubewells & $6(27.3)$ & - Well-sharing & $182(20.9)$ & - Deep tubewells & $298(75.3)$ \\
\hline - Deep tubewells & $5(22.7)$ & $\begin{array}{l}\text { - Arsenic removal } \\
\text { filters }\end{array}$ & $5(22.7)$ & - Household arsenic removal & $130(14.9)$ & • Well-sharing & $3(0.8)$ \\
\hline - Pond sand filters & $3(13.6)$ & - Pond sand filters & $4(18.2)$ & - Community arsenic removal & $117(13.4)$ & - Dug wells & $1(0.3)$ \\
\hline $\begin{array}{l}\text { - Rainwater } \\
\text { harvesting }\end{array}$ & $3(13.6)$ & $\begin{array}{l}\text { - Rainwater } \\
\text { harvesting }\end{array}$ & $4(18.2)$ & - Rural piped water supply & $112(12.8)$ & $\begin{array}{l}\text { - Pond/river water } \\
\text { (untreated) }\end{array}$ & $3(0.8)$ \\
\hline - Dug wells & $2(9.1)$ & - Dug wells & $1(4.5)$ & - Pond sand filters & $106(12.2)$ & - Untested wells & $2(0.5)$ \\
\hline \multirow[t]{4}{*}{$\begin{array}{l}\text { - Arsenic removal } \\
\text { filters }\end{array}$} & $1(4.5)$ & $\begin{array}{l}\text { - Rural piped } \\
\text { water supply }\end{array}$ & $1(4.5)$ & - Rainwater harvesting & $104(11.9)$ & $\begin{array}{l}\text { - As. contaminated } \\
\text { wells }\end{array}$ & $89(22.5)$ \\
\hline & & - Sodis & $1(4.5)$ & - Dug wells & $81(9.3)$ & & \\
\hline & & & & - Deep tubewells & $37(4.2)$ & & \\
\hline & & & & - Bottled water & $3(0.3)$ & & \\
\hline
\end{tabular}

Sodis solar water disinfection 
Table 4 Advantages of arsenic mitigation options

Stakeholders $\quad f(\%) \quad f(\%) \quad$ End users

Rural piped water supply ${ }^{\mathrm{a}}$ (stakeholders $N=22$ and end users $N=125$ )

- People are willing to pay

- Long-term option from surface water

- Less costly than deep tubewells

- Taste/smell/color/temperature is good

59 (47.2)

- Good water quality (unspecific)

49 (39.2)

- No/less illness

17 (13.6)

- Good for cooking

$11(8.8)$

- Other

Deep tubewells $\mathrm{s}^{\mathrm{a}}$ (stakeholders $N=22$ and end users $N=396$ )

- Most sustainable (most socially accepted)

- Taste is good

- Easy use and maintenance (same behavior as STWs)

- Temperature is good

$303(76.5)$

- Also preferred by GoB (although against policy)

Pond sand filters ${ }^{\mathrm{a}}$ (stakeholders $N=22$ and end users $N=124$ )

- Feasible in the coastal area

- Nice to meet and see people

$60(15.2)$

- Not effortful and time-consuming

$36(9.1)$

- Not costly

$6(1.5)$

- Other good water qualities

30 (7.6)

- Arsenic-safe $85(68.5)$

- No/less iron 54 (43.5)

- Taste/smell/color/temperature is good 47 (37.9)

- No/less illness

45 (36.3)

- Good water quality (unspecific)

$39(31.5)$

- Good for cooking

$11(8.9)$

- Other

Dug wells ${ }^{\mathrm{a}}$ (stakeholders $N=22$ and end users $N=124$ )

- Have been used in Bangladeshi culture for years

- Arsenic-safe

$112(91.1)$

- No/less iron

$111(90.2)$

- Taste/smell/color/temperature is good

- Good water quality (unspecific)

- No/less illness

- Good for cooking

- Other

- No advantage

- Good for cooking

- Other

- No advantage

Household arsenic removal filters ${ }^{\mathrm{a}}$ (end users $N=126$ )

- Arsenic-safe

- No/less iron

- Taste/smell/color/temperature is good

- Good water quality (unspecific)

- No/less illness

- Good for cooking 
Table 4 (continued)

\begin{tabular}{|c|c|c|c|}
\hline Stakeholders & $f(\%)$ & End users & $f(\%)$ \\
\hline & & \multicolumn{2}{|c|}{ Community arsenic removal filters $^{\mathrm{a}}$ (end users $N=125$ ) } \\
\hline & & - Arsenic-safe & $99(79.2)$ \\
\hline & & - No/less iron & $70(56)$ \\
\hline & & - No/less illness & $52(41.6)$ \\
\hline & & - Taste/smell/color/temperature is good & $50(40)$ \\
\hline & & - Good water quality (unspecific) & $50(40)$ \\
\hline & & - Other & $1(0.8)$ \\
\hline \multicolumn{4}{|c|}{ Well-sharing ${ }^{\mathrm{a}}$ (end users $N=125$ ) } \\
\hline & & - Arsenic-safe & $88(70.4)$ \\
\hline & & - Taste/smell/color/temperature is good & $70(56)$ \\
\hline & & - No/less iron & $60(48)$ \\
\hline & & - No/less illness & $32(25.6)$ \\
\hline & & - Good water quality (unspecific) & $26(20.8)$ \\
\hline & & - Good for cooking & $11(8.8)$ \\
\hline & & - Other & $10(8)$ \\
\hline & & - No advantage & $3(2.4)$ \\
\hline
\end{tabular}

Sodis ${ }^{\mathrm{a}}$ (stakeholders $N=22$ )

- May be feasible in coastal area

$1(4.5)$

GoB Government of Bangladesh, Sodis solar water disinfection

${ }^{a}$ Multiple responses

Actual costs and end users' willingness to pay for installing or using arsenic mitigation options and testing of arsenic

\section{Willingness to pay (WTP) for installing arsenic mitigation options}

All interviewees were willing to pay for having a new household filter (Table 6). Nearly two-thirds (63.5\%) were willing to pay a maximum of BDT 500 to 2,000 (US\$6.50 to 26.10), and more than half (54.8\%) thought that BDT 500 to 1,100 (US\$6.50 to 14.30 ) was a reasonable price. Interestingly, the WTP for Alcan filters was much higher than for Sono and Read-F filters. Relative to the subsidized costs, nearly all respondents found the lower bounds of the subsidized costs reasonable to pay, while only $5.6 \%$ were willing to pay the highest subsidized cost of BDT 1,100 (US\$14.30) for purchasing a filter.

Less than two-thirds $(61 \%)$ of the respondents with access to rainwater harvesting were willing to pay a maximum of BDT 1,000 to 3,000 (US\$13 to 39.10) for installing this option. Relative to the subsidized installation costs of BDT 656 to 1,640 (US $\$ 21.40$ to $8.60)$, nearly two-thirds $(62.6 \%)$ of the participants reported their WTP this amount as a maximum, while around half of them $(48.8 \%)$ found this price reasonable.

\section{WTP for using arsenic mitigation options}

All study participants with access to a rural piped water supply were willing to pay for using this option. Nearly all of them $(87.2 \%)$ were willing to pay a maximum amount of BDT 50 to 500 (US\$0.65 to 6.50), and most of them (79.2\%) found paying BDT 50 to 100 (US\$0.65 to 1.30) reasonable. Overall, more than one-third (39.2\%) of the respondents were willing to pay the estimated monthly cost for using piped water of BDT 87 (US\$1.13) as a maximum, while $13.6 \%$ even found this a reasonable price.

Most households with access to pond sand filters (75.6 \%) were willing to pay a maximum of BDT 20 to 200 (US\$0.26 to 2.60 ) per month. They found BDT 20 to 100 (US\$0.26 to 1.30) a reasonable charge. Both of these amounts were slightly more than the monthly estimated using cost of BDT 17 (US\$0.20). A total of $8.1 \%$ participants were not willing to pay for usage at all.

Similarly, $9 \%$ of the respondents related to dug wells did not want to pay for monthly usage. Around half $(51.2 \%)$ were willing to pay a maximum of BDT 40 to 500 (US\$0.52 to $6.50)$ and slightly more than half $(54.5 \%)$ reported BDT 20 to 100 (US\$0.26 to 1.30) as a reasonable monthly fee. Approximately one-third (34.7\%) of respondents were willing to pay the estimated monthly using cost of BDT 51 (US\$0.70) as maximum, and $13.7 \%$ found this a reasonable fee.

Nearly two-thirds $(62.4 \%)$ of the surveyed households who had access to community arsenic removal filters were 
Table 5 Disadvantages of arsenic mitigation options

\begin{tabular}{|c|c|c|c|}
\hline Stakeholders & $f(\%)$ & End users & $f(\%)$ \\
\hline \multicolumn{4}{|c|}{ Rural piped water supply ${ }^{\mathrm{a}}$ (stakeholders $N=22$ and end users $N=125$ ) } \\
\hline - Not always feasible (economically/technically) & $3(13.6)$ & - Unavailability of sufficient water & $52(41.6)$ \\
\hline - Maintenance (salary of caretaker) & $1(4.5)$ & - Economic problem & $37(29.6)$ \\
\hline \multirow[t]{6}{*}{ - No willingness to pay (no concept of water cost) } & $1(4.5)$ & - Dissatisfaction with use/maintenance & $36(28.8)$ \\
\hline & & - Distance/effort/time & $22(17.6)$ \\
\hline & & - Water quality concerns & $12(9.6)$ \\
\hline & & - Difficult social situations & $3(2.4)$ \\
\hline & & - Taste/smell/color/temperature & $2(1.6)$ \\
\hline & & - No disadvantage & $35(28)$ \\
\hline \multicolumn{4}{|l|}{ Deep tubewells ${ }^{\mathrm{a}}$ (stakeholders $N=22$ and end users $N=396$ ) } \\
\hline - Decline of groundwater table & $3(13.6)$ & - Distance/effort/time & $273(68.9)$ \\
\hline - Limited technical feasibility (e.g. Northeast region) & $2(9.1)$ & - Bad to meet and see people & $257(64.9)$ \\
\hline - High cost & $2(9.1)$ & - Taste/smell/color/temperature & $51(12.9)$ \\
\hline - Can be contaminated from shallow aquifers & $2(9.1)$ & - Restriction to collect & $37(9.3)$ \\
\hline - Manganese contamination & $1(4.5)$ & - Economic problem & $13(3.3)$ \\
\hline - Often not deep enough & $1(4.5)$ & - Other water qualities concern & $55(13.9)$ \\
\hline
\end{tabular}

- Outdated drilling techniques are used

- Salinity

Pond sand filters ${ }^{\text {a }}$ (stakeholders $N=22$ and end users $N=124$ )

- Microbial contamination

- Maintenance

- People prefer cheaper and simpler solutions

- Not known to rural people

- Limited feasibility (little rain)

- Not very common in Bangladesh

- Not known to rural people

- Only one family can use it

- Not preferred by rural people

Dug wells ${ }^{\mathrm{a}}$ (stakeholders $N=22$ and end users $N=124$ )

- Often contaminated with arsenic

Arsenic removal filters ${ }^{\mathrm{a}}$ (stakeholders $N=22$ )

- Not sustainable
- Distance/effort/time

$82(66.1)$

- Water quality concerns

18 (14.5)

- Difficult social situations

$16(12.9)$

- Taste/smell/color/temperature

$10(8.1)$

5 (4)

3 (2.4)

2 (1.6)

2 (1.6)

22 (17.7)

- No disadvantage

33 (26.8)

- Dissatisfaction with use/maintenance

29 (23.6)

- Unavailability of sufficient water

$20(16.3)$

- Distance/effort/time

$16(13)$

- Difficult social situations

$12(9.8)$

- Water quality concerns

$11(8.9)$

- Taste/smell/color/temperature

- Economic problem

- No disadvantage

69 (55.6)

- Distance/effort/time

$44(35.5)$

- Taste/smell/color/temperature

28 (22.6)

- Water quality concerns

$16(12.9)$

- Difficult social situations

$12(9.7)$

5 (4)

2 (1.6)

- Dissatisfaction with use/maintenance

$4(3.2)$

- Other

$10(8.1)$

- No disadvantage

$52(41.3)$

Household arsenic removal filters ${ }^{\mathrm{a}}$ (end users $N=126$ )

- Dissatisfaction with use/maintenance 
Table 5 (continued)

\begin{tabular}{|c|c|c|c|}
\hline Stakeholders & $f(\%)$ & End users & $f(\%)$ \\
\hline - Not compliant with GoB policy & $1(4.5)$ & - Distance/effort/time & $44(34.9)$ \\
\hline - High cost & $1(4.5)$ & - Economic problem & $14(11.1)$ \\
\hline - Only emergency solution (symptomatic) & $1(4.5)$ & - Taste/smell/color/temperature & $10(7.9)$ \\
\hline \multirow[t]{13}{*}{ - Maintenance (psych. \& material unavailable) } & $1(4.5)$ & - Unavailability of sufficient water & $5(4)$ \\
\hline & & - Water quality concerns & $2(1.6)$ \\
\hline & & - No disadvantage & $38(30.2)$ \\
\hline & & \multicolumn{2}{|c|}{ Community arsenic removal filters $^{\mathrm{a}}$ (end users $N=125$ ) } \\
\hline & & - Distance/effort/time & $76(60.8)$ \\
\hline & & - Economic problem & $30(24)$ \\
\hline & & - Unavailability of sufficient water & $18(14.4)$ \\
\hline & & - Taste/smell/color/temperature & $12(9.6)$ \\
\hline & & - Difficult social situations & $12(9.6)$ \\
\hline & & - Water quality concerns & $8(6.4)$ \\
\hline & & - Dissatisfaction with use/maintenance & $4(3.2)$ \\
\hline & & - Other & $2(1.6)$ \\
\hline & & - No disadvantage & $35(28)$ \\
\hline \multicolumn{4}{|l|}{ Well-sharing $^{\mathrm{a}}$ (end users $N=125$ ) } \\
\hline & & - Distance/effort/time & $80(64)$ \\
\hline & & - Difficult social situations & $48(38.4)$ \\
\hline & & - Water quality concerns & $16(12.8)$ \\
\hline & & - Taste/smell/color/temperature & $6(4.8)$ \\
\hline & & - Unavailability of sufficient water & $4(3.2)$ \\
\hline & & - Other & $1(0.8)$ \\
\hline & & - No disadvantage & $8(6.4)$ \\
\hline
\end{tabular}

Sodis $^{\text {a }}$ (stakeholders $N=22$ )

$1(4.5)$

GoB Government of Bangladesh, Sodis solar water disinfection

${ }^{\text {a }}$ Multiple responses

willing to pay a maximum of BDT 20 to 300 (US\$0.26 to 3.90). Most of them (84\%) considered BDT 10 to 100 (US\$0.13 to 1.30 ) a reasonable charge for monthly usage, while $6.4 \%$ did not want to pay anything at all. Overall, $10.4 \%$ of respondents were willing to pay the estimated monthly BDT 77 (US\$1) as a maximum, while only one respondent found this a reasonable price.

Two-thirds (66.7\%) of participants with household arsenic removal filters were willing to pay BDT 17 to 100 (US\$0.22 to 1.30$)$ as a maximum fee. More than half (54.4\%) found this a reasonable price. However, only one respondent wanted to pay the estimated lowest monthly usage charge of BDT 167 (US\$2.20).

\section{WTP for arsenic testing}

Regarding willingness to pay for arsenic testing, around half $(52.4 \%)$ of the respondents with household filters were willing to pay a maximum of BDT 50 to 100 (US\$0.70 to 1.30). A large majority $(73.8 \%$ ) found BDT 20 to 100 (US\$0.30 to 1.30) a reasonable price. In turn, $12 \%$ of households with access to well-sharing were not willing to pay for well testing. Half $(50.4 \%)$ of the respondents with access to well-sharing were willing to pay a maximum of BDT 25 to 100 (US\$0.33 to 1.30$)$ and two-thirds (68\%) considered BDT 20 to 100 (US\$0.3 to 1.30 ) a reasonable fee. Regarding the subsidized price of BDT 50 (US\$0.70) per test, only $41.6 \%$ of respondents were willing to pay this price.

\section{Discussion}

The present study investigated stakeholders' and end users' preferences concerning arsenic mitigation options in Bangladesh. For this purpose, 22 qualitative stakeholder interviews and two surveys with 1,268 households living in arsenicaffected areas were conducted. These empirical investigations 
Table 6 Actual costs and end users' willingness to pay for installing or using arsenic mitigation options and testing of arsenic in Bangladeshi Taka (BDT)

\begin{tabular}{|c|c|c|c|c|c|c|c|c|}
\hline & \multirow{2}{*}{\multicolumn{2}{|c|}{ Actual costs ${ }^{1}$}} & \multicolumn{6}{|c|}{ End users' willingness to pay } \\
\hline & & & \multicolumn{3}{|c|}{ Maximum price } & \multicolumn{3}{|c|}{ Reasonable price } \\
\hline & Actual & Subsidized & Median $(>0)$ & Min. & Max. & Median $(>0)$ & Min. & Max. \\
\hline \multicolumn{9}{|l|}{ Installing option cost per household ${ }^{1,6}$} \\
\hline - Household arsenic removal filters & $2,700-5,500^{\mathrm{c}}$ & $270-11,00^{3}$ & 500 & 150 & $>2,000$ & 500 & 100 & $>1,100$ \\
\hline Sono $(n=60)$ & $2,700^{\mathrm{c}}$ & $270-5,40^{3}$ & 475 & 150 & $>1,000$ & 388 & 0 & $>700$ \\
\hline Alcan $(n=64)$ & $3,500^{\mathrm{c}}$ & $350-7,00^{3}$ & 700 & 200 & $>1,200$ & 500 & 100 & $>1,000$ \\
\hline Read-F $(n=2)$ & $5,500^{\mathrm{c}}$ & $550-1,100^{3}$ & 1,500 & 1,000 & 2,000 & 800 & 500 & 1,100 \\
\hline - Rainwater harvesting & $6,558^{\mathrm{a}}$ & $656-1,640^{2}$ & 1,000 & 0 & $>3,000$ & 500 & 0 & $>3,000$ \\
\hline \multicolumn{9}{|l|}{ Using option per month per household ${ }^{1}$} \\
\hline - Rural piped water supply & $87^{\mathrm{a}}$ & - & 50 & 10 & 500 & 50 & 10 & $>100$ \\
\hline - Pond sand filters & $17^{\mathrm{a}}$ & - & 20 & 0 & $>200$ & 20 & 0 & $>100$ \\
\hline - Dug wells & $51^{\mathrm{a}}$ & - & 40 & 0 & $>500$ & 20 & 0 & $>100$ \\
\hline - Community arsenic removal filters & $77^{4}$ & - & 20 & 0 & 300 & 10 & 0 & 100 \\
\hline - Household arsenic removal filters & $167-490^{4}$ & - & 17 & 2 & $>100$ & 17 & 2 & 100 \\
\hline Sono $(n=60)$ & $450^{4}$ & - & 17 & 3 & $>83$ & 17 & 3 & $>67$ \\
\hline Alcan $(n=64)$ & $490^{4}$ & - & 17 & 2 & $>100$ & 17 & 2 & 100 \\
\hline Read-F $(n=2)$ & $167^{4}$ & - & 3 & 3 & 3 & 3 & 2 & 3 \\
\hline - Rainwater harvesting ${ }^{5}$ & $16^{\mathrm{a}}$ & - & 33.3 & 3 & 833 & - & - & - \\
\hline - Well-sharing ${ }^{5}$ & - & - & 8.3 & 1 & 50 & - & - & - \\
\hline - Deep tubewells ${ }^{5}$ & $6^{\mathrm{a}}$ & - & 15 & 10 & 20 & - & - & - \\
\hline \multicolumn{9}{|l|}{ Water testing for arsenic per test ${ }^{1}$} \\
\hline - Household filters & $153^{\mathrm{f}}$ or $767^{\mathrm{h}, 7}$ & $<50^{\mathrm{g}}$ & 50 & 0 & $>100$ & 20 & 0 & $>100$ \\
\hline - Well-sharing & & & 25 & 0 & $>100$ & 20 & 0 & $>100$ \\
\hline
\end{tabular}

U\$1=76.70 BDT (currency converted on 28 April 2013 from http://www.oanda.com/currency/converter/)

${ }^{1}$ Calculations were computed by the authors by consulting the following documents: ${ }^{\mathrm{a}}$ UNICEF (2011); ${ }^{\mathrm{b}} \mathrm{PSU}$ and LGD (2011); ${ }^{\mathrm{c}}$ UNICEF et al. (2010);

${ }^{\mathrm{d}}$ PAC and Pathways (2009); ${ }^{\mathrm{e}}$ Johnston et al. (2010); ${ }^{\mathrm{f}}$ van Geen et al. (2013); ${ }^{\mathrm{g}}$ BBS and UNICEF (2011) and ${ }^{\mathrm{h}}$ UNICEF 2000

${ }^{2}$ Calculation based on the national water supply cost-sharing strategy of $75-90 \%$ discount $^{\mathrm{b}}$

${ }^{3}$ On the DART project contribution scheme, $10-20 \%$ of the actual cost for household filters and 3-6\% for community filters ${ }^{\mathrm{d}, \mathrm{e}}$

${ }^{4}$ Changing filter media: community filters: 23,010 BDT (every 6 months) ${ }^{\text {ce }}$, Sono: need to replace whole unit (every 6 months) ${ }^{\text {c,d }}$, Alcan: 2,940 BDT (every 6 months) $^{\mathrm{c}, \mathrm{d}}$, Read-F: 5,000 BDT (every 30 months) ${ }^{\mathrm{c}, \mathrm{d}}$

${ }^{5}$ End users paid for this option per month

${ }^{6}$ Installation of the remaining six options was not collected (for details: please see the Methods section of the study along with Table 2)

${ }^{7}$ Private laboratories can charge this amount per arsenic testing analysis

revealed that stakeholders and end users converge in their preferences concerning the rural piped water supply and deep tubewells, whereas well-sharing was most preferred by end users but not to the same extent by stakeholders. Pond sand filters, rainwater harvesting and arsenic removal options overall received only moderate support by stakeholders and end users. Finally, dug wells were the least preferred by both stakeholders and end users. Details about the preferences concerning the different options are discussed below.

Most preferred: options for sustainable mitigation

Of all arsenic mitigation options, stakeholders showed the greatest preference for a rural piped water supply, which confirms previous findings (Ahmad et al. 2006; Hoque et al. 2004; Inauen et al. 2013a). They liked that it represents an improved water supply and allows for easy water quality monitoring. End users overall showed a moderate preference for this option. However, of households with access to this option, the great majority $(90 \%)$ preferred it most. This result is also reflected by its high user rates (Inauen et al. 2013a). Still one disadvantage mentioned by end users must be addressed: the unavailability of sufficient water sometimes. Rural piped water supply systems usually only provide water two times a day. One reason for this is to keep electricity costs at a minimum. Another is the unreliable availability of electricity in Bangladesh, particularly in rural areas. Solar energy may be an alternative to overcome the latter. Interestingly, even though one stakeholder 
claimed otherwise, all end users showed some WTP for using piped water. Only $40 \%$ were willing to pay the estimated cost of BDT 87 (US\$1.13) or more, however, which is consistent with previous findings (Ahmad et al. 2005; Inauen et al. 2013a). Still, people who would like to contribute lower amounts may do so by sharing a stand post with other households. In fact, the findings of Inauen et al. (2013a) indicate that some people already do: Nearly all $(97 \%)$ of the users of the rural piped water supply were paying an average of BDT 62 (US\$0.81) for monthly use (Inauen et al. 2013a). Nevertheless, high initial costs and the technical complexity of this option remain major hurdles to be taken before the rural piped water supply can be implemented in a more widespread manner (Ahmad et al. 2005; Kabir and Howard 2007).

Deep tubewells were identified as the preferred option by almost as many stakeholders as the rural piped water supply, but the preference was not as unanimous. Some noted reservations were their high installation cost, regional technical feasibility and risk of deep aquifer pollution. The cost of deep tubewells is indeed high, but they are still considered a costeffective option compared to other arsenic mitigation options (Ravenscroft et al. 2013; UNICEF et al. 2010). While the technical feasibility is not present in every area of Bangladesh (Burgess et al. 2010; Ravenscroft et al. 2013), the concern about groundwater depletion by drinking water consumption has received little scientific support, provided it is not used for irrigation (Harvey et al. 2002; Radloff et al. 2011; Burgess et al. 2010; Ravenscroft et al. 2013). Proponents of deep tubewells preferred them mostly for their sustainability, easy use and maintenance, which is consistent with previous findings (Kabir and Howard 2007; Rahman and Al-Muyeed 2009). End users clearly found deep tubewells the most preferred arsenic mitigation option, which corroborates findings from other studies (e.g., Ahmad et al. 2006; Inauen et al. 2013a; Mosler et al. 2010). They like the good water quality of deep tubewell water, especially the taste and temperature, and also the economic and easy maintenance benefits of this option. Regarding sharing of installation costs, people are charged only BDT 4,500 (US\$58.70) by the DPHE for installing a deep tubewell (DPHE 2013). Wealthier people generally provide most of the cost contribution, which is in line with Inauen et al. (2013a) who found that $80 \%$ of the households did not contribute to installation costs. Major problems, however, were the distance and time to collect water, which have also been identified by other studies (e.g., Mosler et al. 2010; Shafiquzzaman et al. 2009). This problem can be solved by reducing the distance to the wells (Mosler et al. 2010) or by using commitment-enhancing behaviorchange strategies to promote the use of existing wells (Inauen and Mosler 2013; Inauen et al. 2013c).

Well-sharing was the most preferred mitigation option in the first end user study. This is consistent with the findings of Ahmed et al. (2006) and van Geen et al. (2002) that this option is very popular among Bangladeshi people. Among the participants related to this option, nearly all $(87.1 \%)$ preferred it the most, and even $9 \%$ of households with primary access to other options preferred it. The major advantages named were the good taste, smell, color and temperature of the water and that the water contained no or less iron. In line with previous research (Hoque et al. 2004; Inauen et al. 2013a; van Geen et al. 2002), end users also identified two impediments to using this option: large distances, resulting in effort and time to collect water, and difficult social situations. Both of these problems seem to be more pronounced for well-sharing than for other options. The difficult social situations refer to the fact that well-sharing may not always be acceptable culturally, e.g., because of purdah (religious barriers), which does not permit women go to outside their homes to collect water (Hoque et al. 2004; Mosler et al. 2010). Mosler et al. (2010) suggest having special opening hours for women to collect water. Furthermore, the responses indicated that for some households it is considered shameful to collect water from other people's houses. Both the distance and social problems may be overcome by installing wells with multiple hand pumps to people's homesteads.

Moderately preferred: emergency options and solutions for the coastal regions

Stakeholders rated household and community arsenic removal options as their least preferable option. Reasons named were their low sustainability due to problems with maintenance, which confirms the findings of Kabir and Howard (2007). A further problem is their high cost, which replicates the findings of Johnston et al. (2010). Altogether, stakeholders only recommended them as emergency options, i.e., for highly contaminated areas where other options are hardly feasible. For end users, in contrast, household filters were the second most preferred mitigation option. However, this result may be somewhat biased because of the high refusal rate in the household filter group (Inauen et al. 2013a). In our sample, end users with household filters were very satisfied with water quality (e.g., less arsenic and iron, good taste). Still, end users perceived two major problems for using filters: dissatisfaction with the use and maintenance as well as effort and time. This result is in line with the findings of other studies, e.g., Choudhury (2010), Johnston et al. (2010) and Shafiquzzaman et al. (2009). Regarding WTP for having a new household filter, all households were willing to pay some money for it, but only a few households were willing to pay the required amount for maintaining or buying a household filter.

A community filter was the third rated option by the end users. Most end users liked the water quality. In turn, end users were concerned with the long distances, effort and time to collect water, along with economic difficulties, unavailability of sufficient water and difficult social 
situations. With regard to WTP for using this option, the majority were willing to pay a maximum of BDT 20 (US\$0.26), which again does not match the actual monthly usage charge of BDT 77 (US\$1).

A pond sand filter was preferred by as many stakeholders as opponents, while it was preferred little by end users. Some end users liked the water quality, but microbial contamination was identified as the major problem of this option by the stakeholders. This is consistent with the findings of Alam and Rahman (2010) that $77 \%$ of pond sand filters suffered from this problem. One major water quality concern for end users was dissatisfaction with the taste, smell, color and temperature of the water from pond sand filters. However, the most severe difficulty for them was the great distances and related effort and time to collect water. This is in line with the findings of Harun and Kabir (2013), who also found long waiting time and walking distance as the major problems to collecting water from pond sand filters. To mitigate this, the villagers may consider recruiting a van driver for collecting and supplying water for them from the pond sand filters for a monthly fee. However, WTP results suggest that a majority of the end users had low WTP for water from pond sand filters. It is important to note that no end users without access to pond sand filters rated this option, which indicates that many people do not know this option. This is probably due to the fact that pond sand filters are mostly installed in the coastal areas of Bangladesh where groundwater is saline and therefore not feasible for use. For the said regions, they may be recommended for further installment (e.g., Harun and Kabir 2013), but it is a prerequisite to accompany their installation with evidence-based behaviorchange interventions (Inauen and Mosler 2013; Inauen et al. 2013a, c, for suggestions).

Rainwater harvesting was preferred by as many stakeholders as it was opposed by, while it was preferred by a medium number of end users. Interestingly, one-third of the end users who currently used rainwater harvesting preferred other options, perhaps because their rainwater harvesters were broken or out of order (Kabir and Howard 2007). According to the end users, this option provides good quality water, but some mention dissatisfaction with the water, possibly due to microbial contamination (Alam and Rahman 2010). More than two-thirds of end users found several disadvantages of this option, including dissatisfaction with the use or maintenance and the unavailability of sufficient water. Stakeholders also identified the problem of limited feasibility owing to little rain. Furthermore, they mentioned that this option is not known to the rural people. Similar to pond sand filters, stakeholders suggested rainwater harvesting for the coastal regions, and this confirms the findings of Harun and Kabir (2013). Nearly all end users showed some WTP for installing this option. However, less than two-thirds were willing to pay even the subsidized cost of BDT 1,640 (US\$21.40).

Least preferred: dug wells

Only a few stakeholders named dug wells as their preferred option. Some stakeholders considered mentioned advantages of dug wells, including small space requirements for installation, easy maintenance and their belonging to traditional Bangladeshi culture. One major problem they identified was that dug wells often face microbial contamination (Alam and Rahman 2010, 2011; Howard et al. 2006). Similar to the stakeholders, end users rated dug wells as the least preferred option, which is also reflected by low user rates (Inauen et al. 2013a). It is also notable that only $60 \%$ of end users with access to this option actually preferred it. End users mentioned very low satisfaction with the water quality. For instance, the water's taste, smell, color and temperature were rated very low, which is in line with the previous research (Alam and Rahman 2011; Inauen et al. 2013a). From an end users' perspective, the major problem related to use of this option was distance, effort and time along with some other problems, such as difficult social situations and unavailability of sufficient water. End users had a medium level of WTP for monthly usage of dug wells. Most of them were not willing to pay the estimated usage cost of BDT 51 (US\$0.70) per month. Overall, the available research on dug wells indicates that they are neither recommendable from a public health point of view nor are they preferred by stakeholders or end users.

\section{Strengths and limitations of the study}

A strength of the present study is that so far no study has given attention to both stakeholders' and end users' preferences simultaneously. Taking into account both perspectives allows drawing more comprehensive recommendations for designing and implementing more appropriate arsenic mitigation strategies. The present study also has some limitations, however. Some important stakeholders who have been playing a vital role in arsenic mitigation in Bangladesh were not included in this analysis. Future studies should plan for a longer interview phase so that all important stakeholders can be included. Although overall refusal was low, another shortcoming is the high survey refusal rate (approximately $30 \%$ ) of respondents with household arsenic removal filters. This may have caused some positive bias in the result for this option (Inauen et al. 2013a). It will therefore be helpful to validate these results with further studies with more representative samples of household filter owners. Furthermore, our results may be positively biased for deep tubewell preference because of 
over-representation compared to other mitigation options. A further limitation concerns the assessment questions that were used in the two household surveys. In particular, the question asking for the most preferred mitigation option was measured differently in two surveys. Therefore, the results of the two studies are not fully comparable. Similarly, the preference ratings of mitigation options of stakeholders and end users are not fully comparable. This is inherent in their roles as experts and users. Stakeholders were experts in the field of arsenic mitigation; therefore, they knew all the options. For the end users, however, it was likely that they only knew the options installed in their living areas. Finally, the willingness to pay measures of the study were rather straightforward. Replicating the results of the present study with quantitative methods is therefore recommended.

\section{Conclusion}

This study provided insights into stakeholders' and end users' preferences concerning the eight most implemented arsenic mitigation options in Bangladesh. The study revealed that the overall most preferred options by stakeholders and end users are deep tubewells, well-sharing and a rural piped water supply. To advance arsenic mitigation, it is vital to prioritize the installation of the most preferred options rather than the least preferred. For the poorly preferred options (dug wells, pond sand filters and rainwater harvesters), further technological improvements are required, for which the above results give some indications. Furthermore, it is strongly recommended to apply theory- and evidence-based behavior-change strategies alongside the implementation of new mitigation options in order to increase people's use and maintenance of the mitigation options (Inauen and Mosler 2013). Most importantly, collaboration among all involved stakeholders and taking into account end users' preferences are urgently needed to maximize the success of arsenic mitigation efforts in Bangladesh.

\footnotetext{
Acknowledgments The authors thank all study participants for taking the time to answer our questions. Furthermore, the authors are very grateful for the field support from the following organizations: Department of Public Health Engineering (DPHE) of the Government of Bangladesh, UNICEF Bangladesh, NGO Forum for Drinking Water Supply \& Sanitation, SHETU Bangladesh, the Rishilpi Development Project, the Society for Disadvantaged Origins (SDO), the Tribedi Women Social Development Association (TWSDA), the Voluntary Association for Welfare and Social Development (VAFWSD) and the Village Education Resource Center (VERC). The first author also warmly thanks the Eawag Partnership Programme (EPP) for awarding him the fellowship that made this research possible. Special thanks go to Prof. Dr. Hans-Joachim Mosler for his constant supervision and valuable advice for carrying out
}

the study. The authors' final gratitude goes to the Eawag: Swiss Federal Institute of Aquatic Science \& Technology for funding this research.

Conflict of interest The authors declare that they do not have any conflict of interest.

\section{References}

Ahmad SA, Sayed MHSU, Barua S, Khan MH, Faruquee MH, Jalil A, Hadi SA, Talukder HK (2001) Arsenic in drinking water and pregnancy outcomes. Environ Health Perspect 109(6):629-631

Ahmad J, Goldar B, Misra S (2005) Value of arsenic-free drinking water to rural households in Bangladesh. J Environ Manag 74:173-185. doi:10.1016/j.jenvman.2004.07.011

Ahmad J, Goldar B, Misra S (2006) Rural communities' preferences for arsenic mitigation options in Bangladesh. J Water Health 4(4):463 477. doi:10.2166/wh.2006.027

Ahmed KM, Bhattacharya P, Hasan MA, Akhter SH, Alam SMM, Bhuyian MAH, Imam MB, Khan AA, Sracek O (2004) Arsenic enrichment in groundwater of the alluvial aquifers in Bangladesh: an overview. Appl Geochem 19:181-200. doi:10.1016/j.apgeochem. 2003.09.006

Ahmed MF, Ahuja S, Alauddin M, Hug SJ, Lloyd JR, Pfaff A, Michler T, Saltikov C, Stute M, van Geen A (2006) Ensuring safe drinking water in Bangladesh. Science 314:1687-1688. doi:10.1126/science. 1133146

Alam MA, Rahman MM (2010) Comparative assessment of four alternative water supply options in arsenic affected areas of Bangladesh. J Civ Eng (IEB) 38(2):191-201, Available at: http://www.jceieb.org. bd/pdfdown/3802009.pdf. Accessed 11 Dec 2013

Alam MA, Rahman MM (2011) Assessment of dug well as an alternative water supply options in arsenic affected areas of Bangladesh. Int $\mathrm{J}$ Civ Environ Eng 11(1):124-137, Available at: http://www. researchgate.net/publication/228486844_ASSESSMENT_OF DUGWELL_AS_AN_ALTERNATIVE_WATER_SUPPLY OPTIONS IN AR SENIC AFFECTED AREAS OF ${ }^{-}$ BANGLADESH/file/32bfe50ddcadc2b3b1.pdf. Accessed $1 \overline{1}$ Dec 2013

Anawar HM, Akai J, Mihaljevič M, Sikder AM, Ahmed G, Tareq SM, Rahman MM (2011) Arsenic contamination in groundwater of Bangladesh: perspectives on geochemical, microbial and anthropogenic issues. Water 3:1050-1076. doi:10.3390/w3041050

Argos M, Kalra T, Rathouz PJ, Chen Y, Pierce B, Parvez F, Islam T, Ahmed A, Zaman MR, Hasan R, Sarwar G, Slavkovich V, van Geen A, Graziano J, Ahsan H (2010) Arsenic exposure from drinking water, and all-cause and chronic-disease mortalities in Bangladesh (HEALS): a prospective cohort study. Lancet 376:252-258. doi:10. 1016/S0140-6736(10)60481-3

Argos M, Kalra T, Pierce BL, Chen Y, Parvez F, Islam T, Ahmed A, Hasan R, Hasan K, Sarwar G, Levy D, Slavkovich V, Graziano JH, Rathouz PJ, Ahsan H (2011) A prospective study of arsenic exposure from drinking water and incidence of skin lesions in Bangladesh. Am J Epidemiol 174(2):185-194. doi:10.1093/aje/ kwr062

Atkins P, Hassan M, Dunn C (2007a) Environmental irony: summoning death in Bangladesh. Environ Plan A 39(11):2699-2714. doi:10. 1068/a38123

Atkins P, Hassan M, Dunn C (2007b) Poisons, pragmatic governance and deliberative democracy: the arsenic crisis in Bangladesh. Geoforum 38(1):155-170. doi:10.1016/j.geoforum.2006.07.009

Bala P, Tarafder P, Azad AK, Anwar AHM (2012) Environment and health hazard of arsenic and their remedies: a review. Bangladesh Res Pub J 7(1):69-79, Available at: http://www. 
bdresearchpublications.com/admin/journal/upload/09317/ 09317.pdf. Accessed 11 Dec 2013

BBS (Bangladesh Bureau of Statistics), UNICEF (2011) Bangladesh National Drinking Water Quality Survey of 2009. BBS and UNICEF, Dhaka, Available at: http://www.unicef.org/bangladesh/ knowledgecentre 6868.htm. Accessed 11 Dec 2013

Bhattacharjee Y (2007) A sluggish response to humanity's biggest mass poisoning. Science 315:1659-1661

Brinkel J, Khan MMH, Kraemer A (2009) A systematic review of arsenic exposure and its social and mental health effects with special reference to Bangladesh. Int J Environ Res Public Health 6:1609-1619. doi:10.3390/ijerph6051609

Burgess WG, Hoque MA, Michael HA, Voss CI, Breit GN, Ahmed KM (2010) Vulnerability of deep groundwater in the Bengal aquifer system to contamination by arsenic. Nat Geosci 3:83-87. doi:10. 1038/NGEO750

Chen Y, Ahsan H (2004) Cancer burden from arsenic in drinking water in Bangladesh. Am J Public Health 94(5):741-744

Chen Y, Graziano JH, Parvez F, Liu M, Slavkovich V, Kalra T, Argos M, Islam T, Ahmed A, Zaman MR, Hasan R, Sarwar G, Levy D, van Geen A, Ahsan H (2011) Arsenic exposure from drinking water and mortality from cardiovascular disease in Bangladesh: prospective cohort study. BMJ 342:d2431. doi:10.1136/bmj.d2431

Choudhury SA (2010) Stocktaking and assessment of selected arsenic removal technologies from drinking water in Bangladesh. Paper presented at the Regional Conference on Appropriate Water Supply, Sanitation, and Hygiene (WASH) Solutions for Informal Settlements and Marginalized Communities, Kathmandu, Nepal, 19-21 May 2010

DPHE (Department of Public Health Engineering) (2013) Functions, policy, strategy, and development partners related information of DPHE. http://www.dphe.gov.bd/index.php. Accessed 11 Dec 2013

Erdfelder E, Faul F, Buchner A (1996) GPOWER: a general power analysis program. Behav Res Methods Instrum Comput 28:1-11. doi:10.3758/BF03203630

Flanagan SV, Johnston RB, Zheng Y (2012) Health and economic impact of arsenic in Bangladesh: implications for mitigation strategy and practice. Bull World Health Organ 90:839-846. doi:10.2471/BLT. 11.101253

GoB (Government of Bangladesh) (2004a) National policy for arsenic mitigation. GoB, Dhaka, Available at: http:/www.dphe.gov.bd/pdf/ National-Policy-for-Arsenic-Mitigation-2004.pdf. Accessed 11 Dec 2013

GoB (2004b) Implementation plan for arsenic mitigation. GoB, Dhaka, Available at: http://users.physics.harvard.edu/ wilson/arsenic/countries/ bangladesh/National $\% 20$ Water\%20Policy $\% 202003 /$ Arsenic $\%$ 20IMPLEM\%20FINAL-23-8-03.pdf. Accessed 11 Dec 2013

Hanchett S (2006) Social aspects of the arsenic contamination of drinking water: a review of knowledge and practice in Bangladesh and West Bengal. In: APSU (eds) Selected papers on the social aspects of arsenic and arsenic mitigation in Bangladesh. Arsenic Policy Support Unit (APSU), Dhaka, Bangladesh, pp 53-84. Available at: http://users.physics. harvard.edu/ wilson/arsenic/references/selected_social_papers. pdf. Accessed 11 Dec 2013

Harun MAYA, Kabir GMM (2013) Evaluating pond sand filter as sustainable drinking water supplier in the southwest costal region of Bangladesh. Appl Water Sci 3:161-166. doi:10.1007/s13201-0120069-7

Harvey CF, Swartz CH, Badruzzaman ABM, Koen-Blute N, Yu W, Ali MA, Jay J, Beckie R, Niedan V, Brabander D, Hemond HF, Ahmed MF (2002) Arsenic mobility and groundwater extraction in Bangladesh. Science 298:1602-1606

Hassan MM, Atkins P, Dunn C (2005) Social implications of arsenic poisoning in Bangladesh. Soc Sci Med 61(10):2201-2211

Hoffmeyer-Zlotnik JHP (2003) New sampling designs and the quality of data. Adv Methodol Stat/Metodološki zvezki 19:205-217
Hoque BA, Hoque MM, Ahmed T, Islam S, Azad AK, Ali N, Hossain M, Hossain MS (2004) Demand based water options for arsenic mitigation: an experience from rural Bangladesh. Public Health 118:70 77. doi:10.1016/S0033-3506(03)00135-5

Hossain MF (2006) Arsenic contamination in Bangladesh - an overview. Agric Ecosyst Environ 113:1-16. doi:10.1016/j.agee.2005.08.034

Howard G, Ahmed MF, Shamsuddin AJ, Mahmud SG, Deere D (2006) Risk assessment of arsenic mitigation options in Bangladesh. J Health Popul Nutr 24(3):346-355.

Inauen J, Mosler H-J (2013) Developing and testing theory-based and evidence-based interventions to promote switching to arsenic-safe wells in Bangladesh. J Health Psychol. doi:10.1177/ 1359105313493811

Inauen J, Hossain MM, Johnston RB, Mosler H-J (2013a) Acceptance and use of eight arsenic-safe drinking water options in Bangladesh. PLoS ONE 8(1):e53640. doi:10.1371/journal.pone.0053640

Inauen J, Tobias R, Mosler H-J (2013b) Predicting water-consumption habits for seven arsenic-safe water options in Bangladesh. BMC Public Health 13:417. doi:10.1186/1471-2458-13-417

Inauen J, Tobias R, Mosler H-J (2013c) The role of commitment strength in enhancing safe water consumption: mediation analysis of a cluster-randomized trial. Br J Health Psychol. doi:10.1111/bjhp. 12068

Johnston RB, Sarker MH (2007) Arsenic mitigation in Bangladesh: national screening data and case studies in three upazilas. J Environ Sci Health Part A Toxic/Hazard Subst Environ Eng 42: 1889-1896. doi:10.1080/10934520701567155

Johnston RB, Hanchett S, Khan MH (2010) The socio-economics of arsenic removal. Nat Geosci 3:2-3. doi:10.1038/ngeo735

Kabir A, Howard G (2007) Sustainability of arsenic mitigation in Bangladesh: results of a functionality survey. Int J Environ Health Res 17(3):207-218. doi:10.1080/09603120701254904

Kabir A, Johnston R, Ogata R, Tsushima S (2005) Practical approach for efficient safe water option. JICA (Japan International Cooperation Agency) and UNICEF, Dhaka

Milton AH, Hore SK, Hossain MZ, Rahman M (2012) Bangladesh arsenic mitigation programs: lessons from the past. Emerg Health Threats J 5:7269. doi:10.3402/ehtj.v5i0.7269

Mitra AK, Bose BK, Kabir H, Das BK, Hussain M (2002) Arsenicrelated health problems among hospital patients in Southern Bangladesh. J Health Popul Nutr 20(3):198-204

Mosler HJ, Blöchliger OR, Inauen J (2010) Personal, social, and situational factors influencing the consumption of drinking water from arsenic-safe deep tubewells in Bangladesh. J Environ Manag 91: 1316-1323. doi:10.1016/j.jenvman.2010.02.012

Nahar N, Hossain F, Hossain MD (2008) Health and socioeconomic effects of groundwater arsenic contamination in rural Bangladesh: new evidence from field surveys. J Environ Health 70(9):42-47

Naujokas MF, Anderson B, Ahsan H, Aposhian HV, Graziano JH, Thompson C, Suk WA (2013) The broad scope of health effects from chronic arsenic exposure: update on a worldwide public health problem. Environ Health Perspect 121(3):295-302

PAC (Planning Alternatives for Change), Pathways Consulting Services Ltd (2009) Final report: social and economic assessment of arsenic removal technologies. UNICEF, PAC and PCSL, Dhaka

Parvez F, Chen Y, Argos M, Hussain AZMI, Momotaj H, Dhar R, van Geen A, Graziano JH, Ahsan H (2006) Prevalence of arsenic exposure from drinking water and awareness of its health risks in a Bangladeshi population: results from a large population-based study. Environ Health Perspect 114(3):355-359. doi:10.1289/ehp.7903

Parvez F, Wasserman GA, Factor-Litvak P, Liu X, Slavkovich V, Siddique AB, Sultana R, Sultana R, Islam T, Levy D, Mey JL, van Geen A, Khan K, Kline J, Ahsan H, Graziano JH (2011) Arsenic exposure and motor function among children in Bangladesh. Environ Health Perspect 119(11):1665-1670. doi:10.1289/ehp. 1103548 
PSU (Policy Support Unit), LGD (Local Government Division) (2011) National cost sharing strategy for water supply and sanitation in Bangladesh. LGD, GoB, Dhaka, Available at: http://www.psu-wss. org/assets/book/ncsseng.pdf. Accessed 11 Dec 2013

Radloff KA, Zheng Y, Michael HA, Stute M, Bostick BC et al (2011) Arsenic migration to deep groundwater in Bangladesh influenced by adsorption and water demand. Nat Geosci 4:793-798. doi:10.1038/ NGEO1283

Rahman MH, Al-Muyeed A (2009) Arsenic crisis of Bangladesh and mitigation measures. J Water Supply Res Technol AQUA 58(3): 228-245. doi:10.2166/aqua.2009.031

Ravenscroft P, McArthur JM, Hoque MA (2013) Stable groundwater quality in deep aquifers of Southern Bangladesh: the case against sustainable abstraction. Sci Total Environ 454-455:627-638. doi: 10.1016/j.scitotenv.2013.02.071

Sarker MMR (2010) Determinants of arsenicosis patients' perception and social implications of arsenic poisoning through groundwater in Bangladesh. Int J Environ Res Public Health 7:3644-3656. doi:10. 3390/ijerph7103644

Shafiquzzaman M, Azam MS, Mishima I, Nakajima J (2009) Technical and social evaluation of arsenic mitigation in rural Bangladesh. $\mathrm{J}$ Health Popul Nutr 27(5):674-683

Smith AH, Steinmaus CM (2009) Health effects of arsenic and chromium in drinking water: recent human findings. Annu Rev Public Health 30:107-122. doi:10.1146/annurev.publhealth. 031308.100143

UNICEF (2000) Arsenic mitigation in Bangladesh - Mediabrief. UNICEF, Dhaka, Available at: http://www.bvsde.ops-oms.org/ enwww/fulltext/recuhidr/arsenic/arsenic.pdf. Accessed 11 Dec 2013

UNICEF (2010) Arsenic mitigation in Bangladesh. UNICEF, Dhaka, Available at: http://www.unicef.org/bangladesh/Arsenic Mitigation_in_Bangladesh.pdf. Accessed 10 Dec 2013
UNICEF (2011) Making economic sense for arsenic mitigation: a case study of Comilla district, Bangladesh. UNICEF, Dhaka, Available at: http://www.unicef.org/bangladesh/knowledgecentre_6872.htm. Accessed 10 Dec 2013

UNICEF, FAO (Food and Agriculture Organization), WHO, WSP (Water and Sanitation Program of the World Bank) (2010) Towards an arsenic safe environment in Bangladesh. Available at: http://www.unicef.org/bangladesh/Towards an arsenic_safe_environ_summary\%28english\%29_22Mar2010. pdf. Accessed 10 Dec 2013

van Geen A, Ahsan H, Homeman AH, Dhar RK, Zheng Y et al (2002) Promotion of well-switching to mitigate the current arsenic crisis in Bangladesh. Bull World Health Organ 80(9):732-737. doi:10.1590/ S0042-96862002000900010

van Geen A, Ahmed KM, Sumon EBA, Singh CK (2013) Towards forprofit testing of groundwater for arsenic in south Asia. Oral presentation at the GeoGen 2013 international conference on towards sustainable safe water supply in developing countries: the challenge of geogenic contaminants and mitigation measures, Addis Ababa, Ethiopia, 5-7 February, 2013

Wasserman GA, Liu X, Parvez F, Ahsan H, Factor-Litvak P, van Geen A et al (2004) Water arsenic exposure and children's intellectual function in Araihazar, Bangladesh. Environ Health Perspect 112(13): 1329-1333. doi:10.1289/ehp.6964

WHO (2008) Guidelines for drinking-water quality: incorporating first and second addenda to third edition. Vol. 1 - Recommendations. WHO, Geneva, Available at: http://www.who.int/water_sanitation health/dwq/gdwq3/en/index. Accessed 01 Oct 2012

WHO (World Health Organization) (2001) Arsenic in drinking water. Fact sheet number 210. Available at: http://www.who. int/mediacentre/factsheets/fs210/en/print.html. Accessed 24 Jan 2008 